\title{
BC First Nations to run own health system
}

$\mathrm{H}$ ealth officials should wait to see how a landmark agreement that gives First Nations in British Columbia the mandate to plan and deliver their own health services plays out before handing over authority in other jurisdictions, Aboriginal health experts say.

It would be "foolish" for other provinces to "jump in with both feet first" to sign similar agreements when they're presented with "a real opportunity to do some research and evaluation and find out how it works and what are the pitfalls and mistakes that will inevitably get made" as a consequence of the transfer, argues Malcolm King, scientific director of the Institute of Aboriginal Peoples' Health at the Canadian Institutes of Health Research.

Over the next two years, the federal government will transfer all of its responsibilities, resources and infrastructure for Aboriginal health in $\mathrm{BC}$ to a new First Nations health authority under the British Columbia Tripartite Framework Agreement on First Nations Health Governance (www.hc-sc.gc.ca /ahc-asc/media/nr-cp/_2011/2011-133 -eng.php).

The agreement will also see Ottawa fork over its budget for BC First Nations health - roughly $\$ 380$ million per year to start - to the new Aboriginal health authority, along with some $\$ 83$ million in provincial funding, explains Joe Gallagher, CEO of the First Nations Health Council.

The first of its kind in Canada, the agreement "establishes clear recognition for the central role First Nations should play in making decisions about the health services delivered to them," and will streamline the administration and integration of those services with the provincial system to close gaps in the care Aboriginal people currently receive, Gallagher says.

King calls the transfer of authority a "natural experiment" and says it should prove to be cost efficient, "because it's combining services that are currently

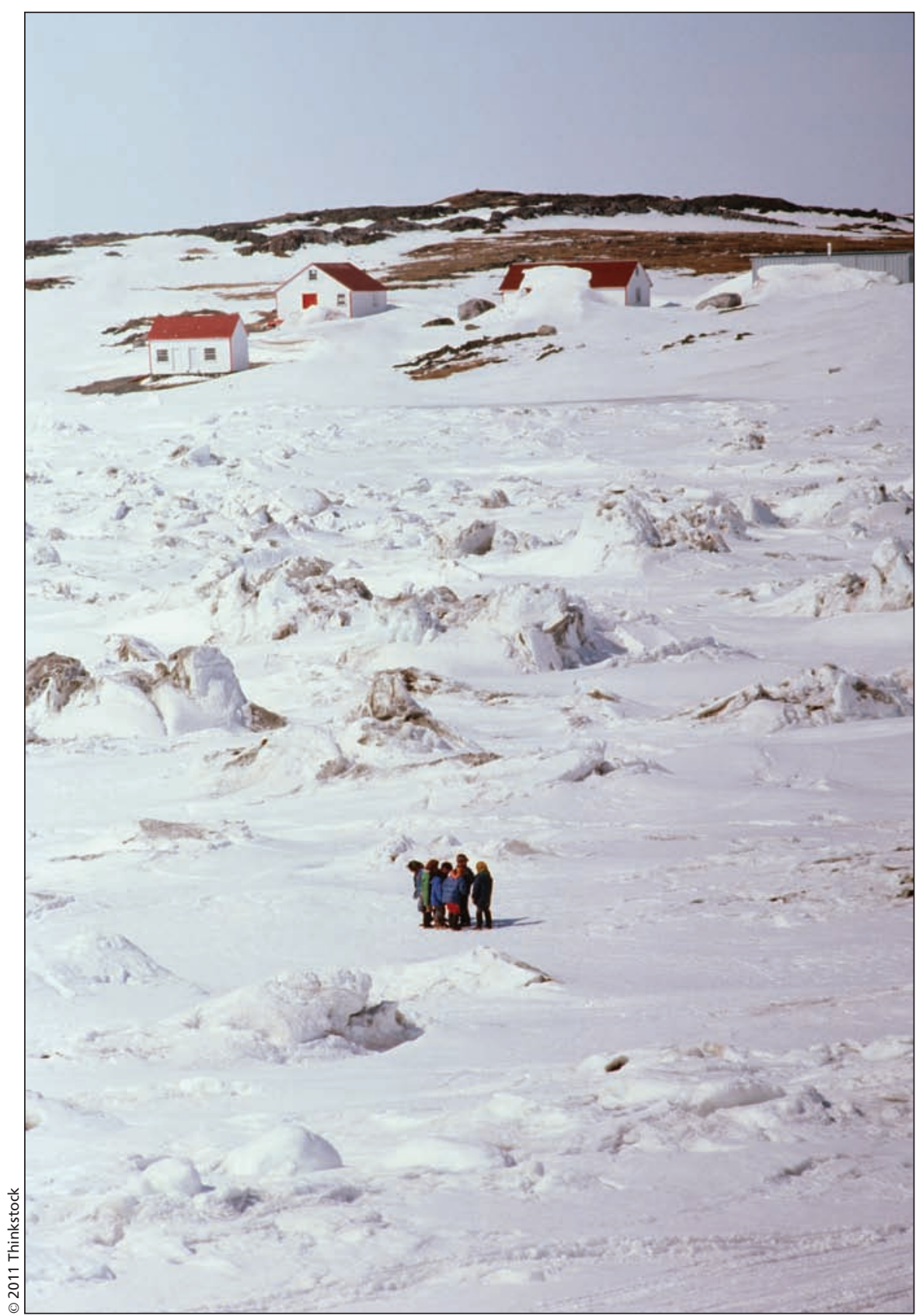

Advocates for more First Nations authority over health care delivery say it will improve health services in remote and rural communities.

provided by the federal and provincial governments, and there's probably some gaps that are not being addressed and probably some overlap that needs to be tightened up."

But the impact on health care staff is unclear, Gallagher says. It will create a "period of uncertainty" for some 230 full-time-equivalent health workers currently employed by Ottawa to deliver services to Aboriginal communities in the province, as it's not clear whether they'll be seconded to the new First Nations health authority as federal 
employees, or brought on as new hires, thus terminating their federal benefits, he says.

The transfer of employees may also have union implications, depending on whether the health authority is considered a provincial or federal entity, Gallagher adds.

Under the agreement, the province's six regional health authorities will continue to provide acute care to Aboriginal people, while the First Nations health authority will be responsible for on-reserve programs, including primary care and public health initiatives.

Previously, those programs were governed by "more than 50 agreements involving about 150 of our 203 communities," says Grand Chief Doug Kelly, chair of the First Nations Health Council. "This is an incredible opportunity for us to look at where our programs are not working and fix them and to look at where our spending isn't getting results and reinvest it to get better ones. I think, in one generation, we're going to see significant improvement in health outcomes for First Nations in BC."

There's currently substantial variation in how health services are delivered in the province, Gallagher says. Some communities have "very flexible agreements with the federal government, and they're already running things on the ground based on how they feel they want to design it, while others have Health Canada providing a lot of the services directly to them."

Because these initiatives are run as independent operations, "there's no opportunity for economies of scale, and there's not a lot of ability to create and retain a workforce, because there's no money for training or professional development," he adds.

Bringing these disparate efforts under a single provincial authority has been no easy task, but staring down the barrel of anticipated federal and provincial budget cuts, First Nations leaders "chose certainty," Kelly says. "They wanted to know what would be available in terms of funding from the federal government and the province of $\mathrm{BC}$ for years to come. They wanted to manage change and not allow change to manage us."

"People can talk about change and debate concepts of a proposal but that's all it will ever be unless leaders can come together and make a decision," he adds. "If other regions across Canada want to pursue this opportunity, that's something they'll have to confront can they create one table, one voice, one decision-making body that will provide direction on a concept and make it a reality?"

Kelly predicts that having a single entity responsible for First Nations health in $\mathrm{BC}$ will improve coordination between existing services and other health authorities, while Gallagher forecasts that it'll be a boon for services in remote communities. "We have health centres in 137 of our 203 communities, and a lot are in rural, remote areas where other British Columbians are living but there are no other provincial facilities. We have an opportunity to have partnerships like never before, where our infrastructure can support provincial health services to benefit both our people and others living in a region."
Such collaboration will require an overhaul of the federal government's existing health information management system for BC First Nations health services to allow transfer of electronic health records with the provincial system, Gallagher adds.

The authority will also participate in provincial and regional planning to ensure the recognition of Aboriginal health priorities in the broader system, and the province has agreed to work with the authority to incorporate First Nations' values, beliefs and traditional healing practices into the delivery of care.

Programs that "balance the best of both worlds" might include the adoption of traditional First Nations' diets to reduce the risk of diabetes, Kelly explains. "Sometimes the most appropriate response to a particular problem is a ceremony or a respected medicine man or woman providing some advice. For us, it's about making sure that when a First Nations person needs surgery they get the best surgeon available to carry out the procedure, and when they need care for the mind, heart or spirit, that they get the best help available from their community." - Lauren Vogel, CMAJ

CMAJ 2011. DOI:10.1503/cmaj.109-4030

The original online version of this article contained an error about the provincial funding to be provided to the new Aboriginal health authority. In fact, the authority will receive a one-time sum of $\$ 83$ million from the province. CMAJ apologizes for any inconvenience this error may have caused. 